\title{
On Pragmatic Failures in Second Language Learning
}

\author{
Xiaorong Luo \\ Foreign Language School, Changchun University of Science and Technology, Changchun, China \\ Email: 1xrlinda301@yahoo.com.cn \\ Jian Gao \\ English Department, the Educational Institute of Jilin Province, Changchun, China \\ Email: bobgao1965@yahoo.cm.cn
}

\begin{abstract}
Pragmatics is the study of the use of language in communication, which includes the study of how the interpretation and use of utterances depends on knowledge of the real world; how speakers use and understand speech acts; how the structure of sentences is influenced by the relationship between the speaker and the hearer. When the pragmatic force of a language is misunderstood, the communication fails, leading to pragmatic failures. The pragmatic failures are composed of pragmatic linguistic failures and social-pragmatic failures. By improving learners' linguistic and communicative competence and cultural quality, the pragmatic failures might be avoided.
\end{abstract}

Index Terms - pragmatic failure, second language learning, linguistic pragmatic failures, social-pragmatic, failures, communication

\section{INTRODUCTION}

Pragmatics is the study of the use of language in communication, particularly the relationships among the sentences and the context and situations in which they are used. Pragmatics includes the study of how the interpretation and use of utterances depends on knowledge of the real world; how speakers use and understand speech acts; how the structure of sentences is influenced by the relationship between the speaker and the hearer. The definition tells us that pragmatics stresses on the relationships among the utterances and the context and the speaker's intention. It is unavoidable to fail in cross-cultural communication because one is not likely to understand all that he hears and what he can understand is his own utterances. When the pragmatic force of a language is misunderstood, for example, if an apology is interpreted as an excuse, the communication fails, which is called pragmatic failures. Pragmatic failures can be divided into two types: pragmatic linguistic failures and socio-pragmatic failures. By pragmatic linguistic failure, we mean that the failures result from the fact that what the speaker says does not agree with the habit of the native speaker, by socio-pragmatic failure, we mean the utterances do not agree with the social culture, customs of the native speaker's.

\section{LingUistiC PRAGMATIC FAILURES}

Second language learners are used to selecting the language materials in the target language to communicate in their own thinking set. Many pragmatic failures occur because English and Chinese are different in systems and the language proficiency of Chinese students is restricted. These failures prevent the communications sometimes, and sometimes English people may understand the speaker's meaning, but what the speaker said does not agree with the English language habit, making the utterance difficult to accept.

\section{A. Linguistic Pragmatic Failures from the Phonetic Transfer}

Influenced by the accent and pronouncing habit, Chinese students often mispronounce / $\phi /$ and / $/$ as / s / and / d /, because there are no dentals $/ \phi /$ and / / $/$ in Chinese. When pronouncing them, Chinese students are not used to putting the tip of the tongue between the teeth. So the word "thank" is mispronounced as "sank", "they" as "day". Only one sound is mispronounced in these two words, but their meanings have been changed completely. Such acoustic failure would affect the understanding of English.

\section{B. Linguistic Pragmatic Failure from Lexis}

English beginners in China just believe that each Chinese word and phrase has the equivalent word in English. As a matter of fact, most words have many different equivalent forms in the other language according to different context and situation. For example, Chinese character“发展,'is equivalent to "develop" in English. However, "develop" has more than one meaning when it collocates different words in English, such as "develop a habit" (means form a habit), "develop the film" ( means treat the film with chemical substances), "develop a good attitude" (means set up a good 
attitude), etc. All these seem abnormal and absurd to English beginners. It is easy for Chinese students to make transfer from Chinese to English concerning the collocation in this field. If students cannot get the correct understanding of a word, they also can make negative transfer.

\section{Linguistic Pragmatic Failures from Syntax}

The syntax reflects the thinking mode of a nation. As a thinking tool, a language is acquired along with the establishment of thinking ability. Characteristics of a language are inevitable to be reflected in thinking set. To learn a new language implies to establish a new mode of thinking. So learners have to overcome the difficulty of Chinese thinking set and try to think in English. To change it is far more difficult. For example, when we ask someone to do something, there are different expressions in English and Chinese. According to indirect speech act, the more indirect and optional the speech act is, the more polite it will be. Chinese tend to use a more direct and imposing, or less indirect and optional speech act than native speakers do in a similar context of situation. Such as when offering something to eat or drink: Chinese often say "Have another sandwich." While English say "Would you like to have another sandwich?". In order to succeed in communicating, the speech act must agree with English linguistic habit.

\section{SOCIAL-PRAGMATIC FAILURES}

In cross-cultural communication, when we speak a foreign language, though our grammar may be OK, we cannot speak it tactfully and appropriately just because of cultural difference. If we make mistakes in grammar when we speak, we are said to speak badly only; however, if we cannot speak tactfully and appropriately, we are said to behave badly. Therefore, socio-pragmatic failures may lead to communicative failures. Grice (1975) advanced the cooperative Principles: A. Quantity Maxim; B. Quality Maxim; C. Relative Maxim; D. Manner Maxim. He stresses that people can understand and co-operate each other only when they obey the rules in communication. But in daily life, people do violate the cooperative principles for the aim of politeness. After Grice, Leech (1983) put forward the Politeness Principle: A. Tack Maxim; B. Generosity Maxim; C. Approbation Maxim; D. Modesty Maxim; E. Agreement Maxi; F. Sympathy Maxim. In communication, socio-pragmatic failures often results from various social, cultural factors and customs. Sometimes, the speakers break the cooperative principle or violate the politeness principles in communicating. Even, sometimes, the occurrence of socio-pragmatic failures is due to the fact that the speaker and the hearer obey different principles in communication. Influenced by the deep-structure of cultural negative transfer, people always make some cultural mistakes in using language by adopting the way of native cultural sense plus target cultural form and thus caused the socio-pragmatic failures. As mentioned previously, social-pragmatic failure is related much to the background and context. And it's not unusual to be seen in translation.

“巧妇难为无米之炊。(qiaofu nanwei wumizhichui.)

The two versions of translation for it are: A. 'Even the cleverest housewife can not cook a meal without rice.' B. 'Even the cleverest housewife can not make bread without flour.' If the translation is for Chinese readers, version A is OK, if the translator's work is for readers of native English, version B is a better one"( He Ziran,2006, p. 227). Social-pragmatics refers to the pragmatic studies which check the conditions on language that originates from the social and cultural situation. In communication, this consideration is dependent on the speaker's beliefs and his cross-cultural knowledge. There are different pragmatic rules in different linguistic cultures. If the nation-specific pragmatic rules are ignored, the pragmatic failures would occur, affecting the communication.

\section{WAYS TO AVOID PRAgMatic FAILURES}

In cross-cultural communications, in order to make the communications smooth, language learners have to overcome the pragmatic failure by improving their own linguistic competence, communicative competence and their cultural quality.

\section{A. To Improve the Linguistic Competence}

Linguistic competence, by Chomsky, is considered to be the implicit system of rules that constitutes a person's knowledge of a language. This includes a person's ability to create and understand sentences, including sentences they have never heard before, knowledge of what are and what are not sentences of a particular language, and the ability to recognize ambiguous and deviant sentences. Linguistic competence is the basis to master a foreign language. Without it, it is impossible to use the language correctly. Language learners should begin with the linguistic knowledge to improve his linguistic competence. When second language learners' linguistic knowledge increases, their linguistic competence increases, too. The basic requirement of improving learners' linguistic competence is that learners have to master the standard pronunciation, accurate grammatical rules and vocabulary.

\section{B. To Improve the Communicative Competence}

Communicative competence is put forward by Hymes, based on Chomsky's linguistic competence. Hymes (1970) thought it as the knowledge of not only if something is possible in a language, but also the knowledge of whether it is feasible, appropriate or, done in a particular Speech Community. It includes, 1) formal competence--knowledge of the grammar, vocabulary, phonology and semantics of a language. 2) sociocultural competence--knowledge of the 
relationship between language and its nonlinguistic context, knowing how to use and respond appropriately to different types of Speech Acts, such as requests, apologies, thanks and invitations, knowing which Address Forms should be used with different persons one speaks to and in different situations, and so forth. 3) discourse competence --knowing how to begin and how to end the conversations.4)strategic competence--knowledge of communication strategies that can compensate for weakness in other areas. In fact, Hymes' formal competence amounts to Chomsky's grammatical competence, the other three are equal to his pragmatic competence. The former refers to linguistic accuracy and the latter the appropriateness when language is used in a certain context.

Generally speaking, second language learners begin to study and use foreign language after they have mastered their native linguistic competence. Therefore, there must be the influence from L1. In order to overcome the interference from L1, learners have to have the communicative competence of L2. In this way, they would know what to say, how to say on one occasion to make the language they use agree to the linguistic habit and national customs of the target language. The language that learners use would be accurate and appropriate if they had the communicative competence.

\section{To Improve the Cultural Quality}

Language is inseparable from culture. A particular language is associated with a particular culture, the language provides the key to the understanding of the associated culture, and language itself cannot be really learned or fully understood without enough knowledge of the culture in which it is deeply embedded. Without language, culture would not be possible. On the one hand, languages is influenced and shaped by culture; it reflects culture. In the broadest sense, language is the symbolic representation of a people, and it comprises their historical and cultural backgrounds as well as their approach to life and their ways of living and thinking. What needs to be stressed here is that language and culture interact, and that understanding the language requires understanding the culture. Learning a foreign language well means more than merely mastering the pronunciation, grammar, words and idioms. It also means learning to see the world as native speakers of that language see it, learning the ways in which their language reflects the ideas, customs, and behavior of their society, learning to understand their language of the mind. Learning a language, in fact, is inseparable from learning its culture. So language and culture must be studied together, and great efforts must be made in the study of the culture in which the TL operates. Improving our cultural quality may make our language fluent, vivid, and elegant.

\section{REFERENCES}

[1] Chen Linhua. (2004). An introduction to linguistics. Changchun: Jilin University Press.

[2] Dong Fengrun. (2000). Linguistic comparison and interlanguage. Ph. D. dissertation, Beijing University.

[3] E. de. Saussure. (2001). Course in general linguistics. Beijing: Foreign Language Teaching And Research Press.

[4] Grice, H. P. (1975). Logic and conversation, in P. Cole \& J. Morgan(eds.), Syntax and Semantics, l3, 45-46.

[5] Gui Shichun. (1988). Applied linguistics. Changsha: Hunan Education Press.

[6] He Shanfen. (2002). Contrastive studies of English and Chinese language. Shangahi: Shanghai Foreign Language Education Press.

[7] He Ziran. (2006). Notes on pragmatics. Nanjing: Nanjing Normal University Press.

[8] He Ziran. (2003). Pragmatics and English learning. Nanjing: Nanjing Normal University Press.

[9] Hu Zhuanglin. (2002). Linguistics: An advanced course book. Beijing: Beijing University Press.

[10] Hymes. D.H. (1970). On communicative competence. in Brumfit, C.J.\& Johnson,K. (eds) (1972), The communicative approach of language teaching. Oxford: OUP.

[11] Jiang Wangqi. (2003). Contemporary pragmatics. Beijing: Beijing University Press.

[12] Jiang Wangqi. (2002). Pragmatics: Theory and application. Beijing: Beijing University Press.

[13] Lado, R. (1957). Linguistics across cultures: Applied linguistics for language teachers. Ann Arbor, Michigan: University of Michigan.

[14] Lecch. G. (1983). Principles of Pragmatics. London: Longman.

[15] Luo Xiaorong. Liu Fang. (2010). Understanding unsuccessful translation of public signs in Changchun, China. Journal of Culture \& International Languages, 6,41-44.

[16] Qin Xiubai. (2002). Essentials of English stylistics. Shanghai: Shanghai Foreign Language Education Press.

[17] Rod Ellis, R. (1999). Understanding second language acquisition. Shanghai: Shanghai Foreign Language Education Press.

[18] Rod Ellis. (2000). Second language acquisition. Shanghai: Shanghai Foreign Language Education Press.

[19] Wang Dongjin. (2007). Language transfer and the acquisition of English light-verb and noun collocations by Chinese learners. Master's thesis, Chongqing University.

[20] Xiao Liming. (2002). English-Chinese comparative studies and translation. Shanghai: Shanghai Foreign Language Education Press.

Xiaorong Luo was born in Changchun, China in 1963. She received her M.A. degree in linguistics from Changchun University of Science and Technology, China in 2009.

She is currently an associate professor in School of Foreign Languages, Changchun University of Science and Technology. Her interests are concerning the fields of language teaching and applied linguistics. She has published some papers relating to her teaching. 
Jian Gao was born in Changchun, China in 1965. He got his bachelor degree in English teaching from Siping Teachers' College, Siping, Jilin, China in 1984.

He is currently an associate professor in English Department, the Educational Institute of Jilin province, China. His favorite fields are the general linguistics and teaching methodology. His latest publication is The importance of Teaching English Phonetics, and he also did the project on The differences of Chinese and English Phonetics. 